\title{
COMPARATIVE RANDOMIZED CLINICAL STUDY OF ACELLULAR DERMAL MATRIX ALLOGRAFT AND SUBEPITHELIAL CONNECTIVE TISSUE GRAFT AROUND IMMEDIATE DENTAL IMPLANTS: 12-MONTHS CLINICAL AND ESTHETIC OUTCOMES
}

\author{
Waleed Mohamed Abbas*
}

\begin{abstract}
Objectives: The aim of the present study was to compare the clinical outcomes of immediate implant placement in the anterior maxilla with subepithelial connective tissue graft (SCGT) and acellular dermal matrix allograft (ADMA), during a 12-month postsurgical evaluation.

The primary outcome of the study was to assess keratinized mucosa (KM) width changes following the two different clinical protocols. Secondary outcomes were to assess enhancement of the soft tissue using pink esthetic score (PES), changes in bleeding index score and probing depth.

Material and methods: Adult patients were eligible for the study if they needed one immediate implant placement (IIP) replacing a tooth to be extracted with thin gingival biotype within the maxillary anterior region. The patients included in the study were divided into two groups; the first group received IIP simultaneously with subepithelial connective tissue graft while patients in the second group received IIP simultaneously with acellular dermal matrix allograft. Clinical assessments including width of keratinized mucosa (KM), pink esthetic score (PES) bleeding Index (BI) and probing depth (PD) were performed before IIP (baseline) and scheduled 4, 8 and 12 months after implant placement.
\end{abstract}

Results: The means of BI and PD values at the 12 months follow up indicated healthy periimplant soft tissues for both groups. There was no statistically significant difference in KM and PES between both groups through 12 months follow up period.

Conclusions: Using acellular dermal matrix allograft can predictably maintain keratinized mucosa and esthetic outcomes as those achieved using subepithelial connective tissue when performed with immediate dental implants. Acellular dermal matrix allograft can be an alternative to subepithelial connective tissue to maintain soft tissue contour around immediate implant placement in esthetic zone with inherited thin soft tissue biotype.

KEYWORDS: acellular dermal matrix, immediate implants, subepithelial connective tissue, peri-implant keratinized tissue, pink esthetic

* Lecturer of Oral Medicine, Periodontology and Oral Diagnosis, Ain Shams University and Future University. 


\section{INTRODUCTION}

Immediate implant placement is considered a predictable treatment option in terms of survival (Slagter et al., 2014). Many authors showed that the insertion of implants immediately after the extraction is a valuable technique in terms of success and esthetic outcomes (Paolantonio et al., 2001) (Cornelini et al., 2006) (J. et al., 2011). However, immediate dental implant is considered aesthetically risky, as the healing of the alveolar bone may lead to unpredictable changes of the contour and the architecture of the gingival tissue around the implant (Chen and Buser, 2009).

Most of studies focused on hard tissue changes, paying little attention to the soft tissue alterations and final aesthetic outcome (Paolantonio et al., 2001; Araújo et al., 2005; Degidi et al., 2013). Little research is available regarding the influence of tissue biotype or width of the keratinized mucosa on soft tissue changes around immediate implant restoration (Kan et al., 2011). It was suggested that immediate implants in sites with thin gingival biotype could result in a higher aesthetic risk in the form of soft tissue recession when compared to sites with thick gingival biotype (Kan et al., 2011).

IIP in conjunction with SCTG results in sufficient peri-implant mucosa thickness that conceals underlying restorative materials. (Rungcharassaeng et al., 2012)

Various gingival autogenous graft techniques have been used to augment sites that have received immediately placed implants. Esthetic outcomes from these techniques are good, but the procedures require a second surgery for graft harvesting (Landsberg, 1997; Kan, Rungcharassaeng and Lozada, 2005; Chung et al., 2011; Yoshino et al., 2014; Migliorati et al., 2015).

Acellular dermal matrix Allograft (ADMA) is used to treat soft tissue problems such as increasing keratinized tissue around teeth and dental implants, performing soft tissue augmentation, providing root coverage, management of ridge deformities and elimination of gingival melanin pigmentation (Callan and Silverstein, 1998; Batista and Batista, 2001; Batista, Batista and Novaes, 2001; Novaes, Pontes, et al., 2002; Park, 2006, 2010; de Souza et al., 2008; Liu et al., 2014; Agarwal, Tarun Kumar and Mehta, 2015; Puisys et al., 2015). This allograft is a skin preparation from which the cellular component is removed (Borges et al., 2009). The ultra- structural integrity of the extra-cellular matrix is maintained and the collagen and elastin matrices remain undamaged (Becker and Goldstein, 2008). Studies in periodontal surgeries have reported that ADMA is a non-immunogenic scaffold, properly integrates into the host tissue and heals by repopulation and revascularization via preserved vascular channels rather than through a granulation process maturing to scar (Shulman, 1996; Tal, 1999). Healing of ADMA is uneventful and the material is integrated into the tissues (Novaes, Papalexiou, et al., 2002).

Despite the numerous previously mentioned studies that described the benefits of ADMA and subepithelial connective tissue graft (SCTG) separately in soft tissue enhancement around dental implants, there has been lack of investigations into comparative studies of these two treatment modalities around immediate implant in patients with thin gingival biotype.

The present study was conducted to evaluate clinical significance of using acellular dermal matrix in a facially prepared envelope simultaneously with immediate dental implants in the anterior maxilla and its effects on the esthetic outcomes.

Hypothesis: It was hypothesized that the use of acellular dermal matrix allograft (ADMA) will lead to similar clinical and esthetic outcomes as compared to the use of autogenous subepithelial connective tissue graft (SCTG) simultaneously with immediate implant placement (IIP) in the anterior maxilla 


\section{AIM OF THE STUDY}

The aim of the present study was to compare the clinical outcomes of IIP with SCGT and ADMA, during a 12-month postsurgical evaluation.

The primary outcome of the study was to assess keratinized mucosa (KM) width changes around IIP in the anterior maxilla after following two different clinical protocols (ADMA vs. SCTG).

Secondary outcomes were to assess enhancement of the soft tissue using pink esthetic score (PES), changes in bleeding index score and probing depth following the two different clinical protocols.

\section{MATERIALS AND METHODS}

The present study was conducted on 14 patients; with age ranged from 22 to 45 years old and randomized into two equal groups (group1 and group 2). Each patient received one immediate implant in the anterior maxilla. The study protocol was approved by the ethical committee for clinical studies of Faculty of Dentistry, Ain Shams University. Patients were selected according to the inclusion and exclusion criteria from the outpatient clinic of the Faculty of Dentistry, Ain Shams University.

\section{Inclusion criteria:}

- Patients presented with the need for inevitable extraction of a single tooth in the maxillary anterior region with thin soft tissue biotype $(<2 \mathrm{~mm})$.

- Good oral hygiene and good compliance with the plaque- control instructions.

- Natural teeth adjacent to the tooth to be extracted were required to have complete occlusal surfaces and were free from infections.

- The presence of intact buccal bone after tooth extraction as proved by exploring the labial plate of the socket using periodontal probe.
- At least $3 \mathrm{~mm}$ of bone beyond the root apex was required to guarantee implant primary stability.

- Patients' ability to follow the study protocol and willingness to sign an informed consent form.

\section{Exclusion criteria:}

- The presence of a fenestration $\leq 4 \mathrm{~mm}$ apical to the facial alveolar bone crest.

- Acute infection at the tooth site.

- Any systemic diseases or medications that could affect the osseointegration of the dental implants or compromise healing potential.

- Moderate and heavy smokers (>10 cigarettes per day).

An informed consent form was signed by all the patients participating in this study. All patients received comprehensive clinical and radiographic examinations and treatment planning procedures. The preoperative cone beam computed tomography (CBCT) scan of the patients helped to confirm the presence of the need for extraction of a single tooth in the maxillary anterior region that met the previously mentioned inclusion criteria. This study was a randomized, double-blinded clinical trial with an equal allocation rate. Patients who met the eligibility criteria were randomly allocated using computer assisted randomization by Microsoft excel through numbered sealed envelopes into two groups. Both the patient and the evaluator who assessed the clinical parameters were blinded to the group assignment.

\section{Group 1 (Gp 1)}

Each patient received one implant that was placed immediately following tooth extraction, with simultaneous soft tissue augmentation in the facial aspect using subepithelial connective tissue graft (SCTG). 


\section{Group 2 (Gp 2)}

Each patient received one implant that was placed immediately following tooth extraction, with simultaneous soft tissue augmentation in the facial aspect using acellular dermal matrix allograft (ADMA).

\section{Surgical Procedures:}

Following the administration of local anesthetic*, the failing tooth or root was removed atraumatically without flap reflection to preserve the esthetic function of the interdental papillae. Intrasulcular incisions were made around the failing tooth or root to separate the soft tissue attachment from the tooth. To minimize the trauma, the teeth were carefully luxated using periotomes** and removed with forceps; great care was taken to maintain the integrity of the facial bone wall, the surrounding soft tissue and avoiding interdental papillae damage. After the extraction, the sulcus was deepithelialized with the use of a $15 \mathrm{C}$ blade. Subsequently, the sockets were carefully curetted of granulation tissue, and irrigated for 30 seconds with saline ${ }^{* * *}$. Subsequently, a periodontal probe ${ }^{* * * *}$ was used to verify the integrity of bony walls of the socket and the presence of dehiscence or fenestration defects (Chen and Buser, 2009); to be included, all of the four bony walls of the socket should be intact. If a dehiscence defect of the facial bone was $\leq 2 \mathrm{~mm}$, the subject was included in the study (Degidi et al., 2013). Transmucosal sounding of the facial plate of bone was performed to detect the presence of any concavities apical to the socket (Chen and Buser,
2009). If the extraction socket met inclusion criteria, an implant ${ }^{* * * * *}$ was placed after optimal osteotomy preparation through sequential drilling with copious irrigation according to the manufacturer instructions till the desired dimensions were achieved depending on the selected implant (Buser, Martin and Belser, 2004). A partial-thickness envelope was created between the facial bony plate and the gingiva of the extraction site (Kan, Rungcharassaeng and Lozada, 2005) .

For group 1 patient; following the administration of local anesthetic ${ }^{* * * * * *}$ to the donor site, SCTG $\approx 5$ $\mathrm{mm}$ in length, $\approx 5 \mathrm{~mm}$ in width, and $1-2 \mathrm{~mm}$ thickness was harvested from the palate using a single-incision technique (Lorenzana and Allen, 2000). The SCTG was inserted into the prepared envelope space and secured with resorbable sutures (4-0 braided coated glycolide homopolymer violet) ${ }^{* * * * * *}$. While for group 2 patients $\mathrm{ADMA}^{* * * * * * *}$ of the same dimensions as those of the SCTG was inserted and sutured into the prepared envelope space. For both groups, light pressure was applied over the inserted graft with moist gauze for 10 minutes to minimize blood clot and dead space formation between the graft and the underlying bone (Kan, Rungcharassaeng and Lozada, 2005) .

For each patient of both groups; proper healing abutment was screwed to the implant at the end of the surgical procedure; approximation of the papillae was done by figure of eight suture. Postoperative medications were prescribed and instructions were explained for all patients.

\footnotetext{
* Articaine hydrochloride $4 \%$ (Septanest SP, Septodont, Saint-Maur-des-Fossés, Cedex, France).

** Helmut Zepf, Medizitechnik GmbH, Seitingen-Oberflacht, Germany

*** Sodium Chloride 0.9\% (Al Mottahedoon Pharmacy, 10 th Ramadan city, Egypt)

**** Helmut Zepf, Medizitechnik GmbH, Seitingen-Oberflacht, Germany

***** Dentaurum Implants GmbH,Turnstra'e, Ispringen, Germany

$* * * * * *$ Articaine hydrochloride $4 \%$ (Septanest SP, Septodont, Saint-Maur-des-Fossés, Cedex, France).

******* Unicryl, Unimed Sutures, United Medical Industries Co. Ltd, KSA.

******** Tutogen Medical Gmbh, Industriestra-6,91077Neunkirchen a.Br.Germany

********* Zila, 701 Centre Avenue, Fort Collins, USA
} 


\section{Prosthetic procedures:}

After complete soft tissue healing, 2 - 3 weeks later, a temporary prosthesis was fabricated for each patient of both groups using auto polymerizing acrylic resin. Four months after implant placement, the final abutment was screwed and conventional loading was applied using permanent porcelain fused to metal crown.

\section{Baseline and Follow-up evaluations:}

\section{Clinical Assessments}

Clinical examination was conducted by the same examiner to assess bleeding index score (BI) (Mombelli et al., 1987), probing depth (PD) and width of keratinized mucosa (KM) at baseline (before extraction), 4 months and 12 months postsurgical intervals, while pink esthetic score (PES) was conducted at 4,8 and 12 months.

PD was measured at three points (mesio-facial, mid-facial and disto-facial) to the nearest millimeter using plastic periodontal probe*. The average of the three facial points was recorded as the probing depth (PD) (Buser et al. 1990).

While KM on the facial aspect, was measured in millimeters at the mid-facial aspects from the mucogingival junction to the free gingival margin using a periodontal probe (Buser et al. 1990).

The PES comprised the following five variables: mesial papilla, distal papilla, curvature of the facial mucosa, level of the facial mucosa, and root convexity/ soft tissue color and texture at the facial aspect of the implant site (Belser et al., 2009) .

\section{Statistical analysis}

The mean and standard deviation values were calculated for each group in each test. Data were explored for normality using Kolmogorov-Smirnov and Shapiro-Wilk tests, PD and KM data showed parametric (normal) distribution, while BI and PES data showed non-parametric (not-normal) distribution.

For parametric data; Repeated measure ANOVA was used to compare between more than two groups in related samples. Paired sample t-test was used to compare between two groups in related samples. Independent sample t-test was used to compare between two groups in non-related samples.

Two-way ANOVA test was used to test the interactions between different variables.

For non-parametric data; Friedman was used to compare between more than two groups in related samples. Wilcoxon test was used to compare between two groups in related samples. Mann Whitney test was used to compare between two groups in non-related samples.

The significance level was set at $\mathrm{P} \leq 0.05$. Statistical analysis was performed with IBM ${ }^{\circledR}$ SPSS ${ }^{\circledR}$ Statistics Version 20 for Windows.

\section{RESULTS}

The present prospective clinical study showed that implants placed in fresh extraction sockets have a high success rate (100\%) through one year followup and that there were no differences in survival and success rates of implants between both groups.

Out of 14 teeth, 8 were removed due to untreatable caries, 2 teeth for root fracture, 1 tooth for endodontic treatment failure, and 3 residual roots because they were judged unrestorable.

\section{I) Width of Keratinized mucosa (KM):}

No statistically significant difference was found in KM between (Baseline), (4 months) and (12 months) follow up intervals in either (Group 1) or (Group 2) where $(p=0.338)$ and $(\mathrm{p}=0.156)$ respectively. 
Group 1 lost $0.858 \pm 1.199 \mathrm{~mm}$ of $\mathrm{KM}$, while the Group 2 lost an average of $0.357 \pm 1.488 \mathrm{~mm}$.

There was no statistically significant difference between both groups at baseline, 4 months and 12 months follow up intervals where $(\mathrm{p}=0.628)$, $(\mathrm{p}=0.598)$ and $(\mathrm{p}=0.220)$ respectively. Mean and standard deviation (SD) for KM for different tested groups are presented in (Table 1)

\section{Two-way ANOVA:}

Data in table ( 2 ) shows the results of Twoway ANOVA analysis for the interaction of different variables. The results showed that groups had no statistically significant effect at P-value 0.200. Time had no statistically significant effect at P-value
0.459. The interaction between the two variables also had no statistically significant effect at P-value 0.871 .

\section{II)Pink esthetic score (PES):}

No statistically significant difference was found in PES between (4 months), (8 months) and (12 months) follow up intervals in either (Group 1) or (Group 2) where $(p=0.810)$ and $(p=0.135)$ respectively.

There was no statistically significant difference between both groups at 4 months, 8 months and 12 months follow up intervals where $(\mathrm{p}=1),(\mathrm{p}=0.368)$ and $(\mathrm{p}=0.333)$ respectively. Mean and standard deviation (SD) for PES for different tested groups are presented in (Table 3), (Figure 1).

TABLE (1): The mean, standard deviation (SD) values of KM of different groups.

\begin{tabular}{|c|c|c|c|c|c|c|c|}
\hline \multirow{3}{*}{ Variables } & \multicolumn{7}{|c|}{ KM } \\
\hline & \multicolumn{2}{|c|}{ Baseline } & \multicolumn{2}{|c|}{$4 m$} & \multicolumn{2}{|c|}{$12 \mathrm{~m}$} & \multirow[t]{2}{*}{ p-value } \\
\hline & Mean & SD & Mean & SD & Mean & SD & \\
\hline Group 1 & 4.429 & 1.397 & 4.286 & 1.704 & 3.571 & 1.397 & $0.338 n s$ \\
\hline Group 2 & 4.786 & 1.286 & 4.714 & 1.220 & 4.429 & 1.058 & $0.156 \mathrm{~ns}$ \\
\hline p-value & \multicolumn{2}{|c|}{$0.628 n s$} & \multicolumn{2}{|c|}{$0.598 n s$} & \multicolumn{2}{|c|}{$0.220 \mathrm{~ns}$} & \\
\hline
\end{tabular}

*; significant $(p<0.05) \quad n s ;$ non-significant $(p>0.05)$

TABLE (2) Results of Two-way ANOVA for the effect of different variables on KM.

\begin{tabular}{|c|c|c|c|c|c|}
\hline Source & $\begin{array}{c}\text { Type III Sum } \\
\text { of Squares }\end{array}$ & df & Mean Square & F & Sig. \\
\hline Corrected Model & 6.601 & 5 & 1.320 & 0.715 & 0.616 \\
\hline Intercept & 801.720 & 1 & 801.720 & 434.481 & 1.706 \\
\hline Groups & 3.149 & 1 & 3.149 & 0.797 & 0.000 \\
\hline Time & 2.940 & 2 & 1.470 & 0.139 & 0.459 \\
\hline Groups* Time & 0.512 & 2 & 0.256 & & 0.871 \\
\hline Error & 66.429 & 36 & 1.845 & & \\
\hline Total & 874.750 & 42 & & & \\
\hline Corrected Total & 73.030 & 41 & & & \\
\hline
\end{tabular}

df: degrees of freedom $=(n-1), *$ Significant at $P \leq 0.05$ 
TABLE (3): The mean, standard deviation (SD) values of PES of different groups.

\begin{tabular}{|c|c|c|c|c|c|c|c|}
\hline \multirow{3}{*}{ Variables } & \multicolumn{7}{|c|}{ PES } \\
\hline & \multicolumn{2}{|c|}{$4 m$} & \multicolumn{2}{|c|}{$8 m$} & \multicolumn{2}{|c|}{$12 \mathrm{~m}$} & \multirow[t]{2}{*}{ p-value } \\
\hline & Mean & SD & Mean & SD & Mean & SD & \\
\hline Group 1 & 7.000 & 0.816 & 7.143 & 0.690 & 7.429 & 0.787 & $0.810 \mathrm{~ns}$ \\
\hline Group 2 & 7.000 & 0.816 & 7.400 & 0.447 & 7.600 & 0.447 & $0.135 n s$ \\
\hline p-value & \multicolumn{2}{|c|}{ 1ns } & \multicolumn{2}{|c|}{$0.368 n s$} & \multicolumn{2}{|c|}{$0.333 n s$} & \\
\hline
\end{tabular}

*; significant $(p<0.05) \quad n s ;$ non-significant $(p>0.05)$

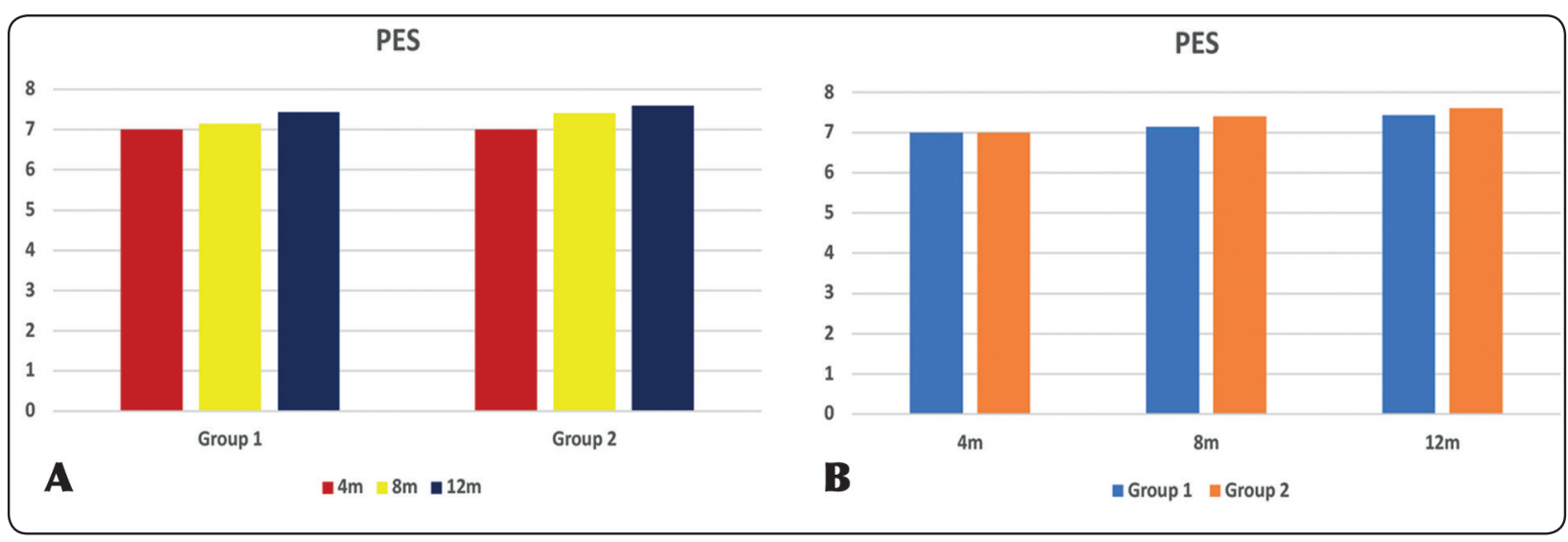

Figure (1): Bar chart representing PES for different groups

\section{III) Bleeding index scores (BI):}

No statistically significant difference was found in BI between (Baseline), (4 months) and (12 months) follow up intervals in either (Group 1) or (Group 2) where $(p=0.431)$ and $(\mathrm{p}=0.288)$ respectively

There was no statistically significant difference between both groups at baseline and at 4 months follow up interval where $(\mathrm{p}=0.104)$ and $(\mathrm{p}=0.197)$ respectively, but there was a statistically significant difference between (Group 1) and (Group 2) at 12 months follow up interval where $(\mathrm{p}=0.008)$. Mean and standard deviation (SD) for BI for different tested groups are presented in (Table 4)

\section{IV) Probing depth (PD):}

No statistically significant difference was found in PD between (Baseline), (4 months) and (12 months) follow up intervals in (Group 1) where $(\mathrm{p}=0.136)$, while there was a statistically significant difference in PD between (Baseline), (4 months) and (12 months) follow up intervals in (Group 2) where $(\mathrm{p}=0.015)$.

There was no statistically significant difference between both groups at baseline, 4 months and 12 months follow up intervals where $(\mathrm{p}=0.881)$, $(\mathrm{p}=0.160)$ and $(\mathrm{p}=0.176)$ respectively. Mean and standard deviation (SD) for PD for different tested groups are presented in (Table 5)

\section{Two-way ANOVA:}

Data in table (6) shows the results of Two-way ANOVA analysis for the interaction of different variables. The results showed that groups had no statistically significant effect at P-value 0.104. Time had no statistically significant effect at P-value 0.053 . The interaction between the two variables also had no statistically significant effect at P-value 0.386. 
TABLE (4): The mean, standard deviation (SD) values of BI of different groups.

\begin{tabular}{|c|c|c|c|c|c|c|c|}
\hline \multirow{3}{*}{ Variables } & \multicolumn{7}{|c|}{ BI } \\
\hline & \multicolumn{2}{|c|}{ Baseline } & \multicolumn{2}{|c|}{$4 m$} & \multicolumn{2}{|c|}{$12 \mathrm{~m}$} & \multirow[t]{2}{*}{ p-value } \\
\hline & Mean & SD & Mean & SD & Mean & SD & \\
\hline Group 1 & 0.738 & 0.131 & 0.786 & 0.284 & 0.929 & 0.189 & $0.431 n s$ \\
\hline Group 2 & 0.866 & 0.149 & 0.920 & 0.242 & 0.666 & 0.193 & $0.228 n s$ \\
\hline p-value & \multicolumn{2}{|c|}{$0.104 n s$} & \multicolumn{2}{|c|}{$0.197 n s$} & \multicolumn{2}{|c|}{$0.008 *$} & \\
\hline
\end{tabular}

*; significant $(p<0.05) \quad n s ;$ non-significant $(p>0.05)$

TABLE (5): The mean, standard deviation (SD) values of PD of different groups.

\begin{tabular}{|c|c|c|c|c|c|c|c|}
\hline \multirow{3}{*}{ Variables } & \multicolumn{7}{|c|}{ PD } \\
\hline & \multicolumn{2}{|c|}{ Baseline } & \multicolumn{2}{|c|}{$4 m$} & \multicolumn{2}{|c|}{$12 \mathrm{~m}$} & \multirow[t]{2}{*}{ p-value } \\
\hline & Mean & SD & Mean & SD & Mean & SD & \\
\hline Group 1 & 2.806 & 0.466 & 3.520 & 0.877 & 2.903 & 0.659 & 0.136ns \\
\hline Group 2 & 2.850 & 0.606 & 2.963 & 0.445 & 2.506 & 0.317 & $0.015 *$ \\
\hline p-value & \multicolumn{2}{|c|}{0.881 ns } & \multicolumn{2}{|c|}{$0.160 \mathrm{~ns}$} & \multicolumn{2}{|c|}{$0.176 n s$} & \\
\hline
\end{tabular}

*; significant $(p<0.05) \quad n s ;$ non-significant $(p>0.05)$

TABLE (6) Results of Two-way ANOVA for the effect of different variables on PD.

\begin{tabular}{|c|c|c|c|c|c|}
\hline Source & $\begin{array}{c}\text { Type III Sum of } \\
\text { Squares }\end{array}$ & df & Mean Square & F & Sig. \\
\hline Corrected Model & 3.861 & 5 & 0.772 & 2.222 & 0.073 \\
\hline Intercept & 359.213 & 1 & 359.213 & 1033.741 & 0.000 \\
\hline Groups & 0.966 & 1 & 0.966 & 2.781 & 0.104 \\
\hline Time & 2.215 & 2 & 0.340 & 0.978 & 0.053 \\
\hline Groups* Time & 0.679 & 2 & 0.347 & & 0.386 \\
\hline Error & 12.510 & 36 & & & \\
\hline Total & 375.584 & 42 & 41 & & \\
\hline Corrected Total & 16.371 & & & & \\
\hline
\end{tabular}

df: degrees of freedom $=(n-1), *$ Significant at $P \leq 0.05$ 


\section{DISCUSSION}

The present randomized study investigated the modification over time (one year follow up) of soft tissue changes after the immediate implant placement (IIP) in fresh extraction sockets with a simplified flapless surgical technique, in association with soft tissue augmentation in a facially prepared partial thickness envelope; using either subepithelial connective tissue graft (SCTG) in Group 1 or acellular dermal matrix allograft (ADMA) in Group 2.

Before implant osteotomy site preparation, the fresh extraction socket was thoroughly degranulated with a surgical curette; the hard socket bone was felt with hand instruments. This minimized the chance of post-operative infection and ensured optimal osseointegration without soft tissue impingement (Chen and Buser, 2009). The gingival walls of the socket orifice were de-epithelialized with the use of a $15 \mathrm{C}$ blade, to expose the underlying bleeding connective tissue to enhance the revascularization of both SCTG and ADMA which were placed in Group 1 and Group 2 patients respectively.

The findings from this study showed that implants placed in fresh extraction sites can provide a safe and successful treatment procedure.

This study showed $100 \%$ survival rate of immediate implants. Comparable implant success rates have been reported with immediate single-tooth replacement (Evans and Chen, 2008; Palattella, Torsello and Cordaro, 2008). This result is also in accordance with Kan et al. who showed a survival rate of $100 \%$ for 35 implants that were placed and immediately restored after tooth extraction (Kan et al., 2011).

Both study groups had slight and not statistically significant decrease in the means of $\mathrm{KM}$ at the end of the study follow-up period and there were no statistically significant differences in the means of KM between both groups at baseline, 4 months and 12 months follow-up intervals. That means that immediate implant with simultaneous soft tissue augmentation using either SCTG or ADMA does not improve the width of keratinized mucosa. That could be attributed to patient selection and the surgical technique used in this study to place the SCTG or ADMA around the immediate implant; where patients included in this study had thin soft tissue biotype $(<2 \mathrm{~mm})$ while the surgical technique was designed to reinforce the keratinized mucosa to stabilize the soft tissue dimensions around the immediate implant and that was the same reported by Caneva and coworkers who used SCTG in their study to reinforce the soft tissue around immediate implants (Caneva et al., 2013).

Regarding KM width changes in the present study; SCTG group lost $0.858 \pm 1.199 \mathrm{~mm}$ of KM, while the ADMA group lost an average of $0.357 \pm$ $1.488 \mathrm{~mm}$. These results were in accordance with a recent clinical study which evaluated the efficacy of ADMA in the augmentation of peri-implant mucosa related to conventional implant placement as compared to an autologous SCTG where SCTG group lost $0.85 \pm 1.13 \mathrm{~mm}$ of $\mathrm{KM}$, while the ADMA group lost an average of $0.45 \pm 1.30 \mathrm{~mm} \mathrm{~mm}$ and no statistically significant differences in terms of width of keratinized mucosa were observed between both treatment modalities.(Hutton et al., 2018)

Placement of a larger SCTG or ADMA will provide more soft tissue quantity, but that requires a partial or full thickness flap release of a larger area over the facial bone to receive it. The longterm consequence of this on the resorption of the sensitive facial bone and soft tissue of the socket is still doubtful.

The main goal of the applied surgical protocol was a predictable contour augmentation of the facial tissue aspect of immediate dental implant, to produce esthetically pleasing soft tissue contours and to prevent mucosal recession. The skills of the implant surgeon play an important role in the esthetic outcome of peri-implant soft tissues. 
The PES evaluates the soft tissue esthetics, including the height of the mesial and distal papillae, the level and curvature of the facial mucosa, root convexity, and tissue color. Most of the implants in the current study fell into the clinically acceptable PES ( $\geq 6$ out of 10) according to Belser, Buser and coworkers indicating an overall successful esthetic outcome (Belser et al., 2009) (Buser et al., 2013). Both groups had PES equals to 7.00 at 4 months follow up interval. A possible explanation of not gaining higher score after 4 months is that the surgical envelope technique used to place either the SCTG or ADMA resulted in more mucosal deformation and scarring of the peri-implant soft tissues. Regarding the total PES score, no significant differences were found between both groups through the 12 months follow up period. This contradicts the findings of Migliorati et al., who found significantly better PES scores when a CTG was applied (Migliorati et al., 2015). The homogenous thickness of ADMA especially in comparison to SCTG may have a positive effect on flap and graft adaptation.

In the present study, there was an increase in the PES total scores - though none statistically significant - for both groups between 4-12months intervals. Our findings were consistent with the findings of Arora \& Ivanovski who showed a significant increase in the PES values at the end of 2 years follow up (Arora and Ivanovski, 2017). While Noelken and coworkers found that the mean PES values improved during the first year followed by a slight decrease after 2 years (Noelken, Kunkel and Wagner, 2011). It may be concluded that proper case selection, the surgical approach, intact facial bone plate with thick biotype, proximal bone levels of adjacent teeth, correct three-dimensional implant positioning and proximal contact are factors responsible for maintaining peri-implant soft tissue and achieving satisfactory esthetic outcomes.

The means of $\mathrm{BI}$ and $\mathrm{PD}$ values at the 12 months follow up indicated healthy peri-implant soft tissues. The reduction in the inflammatory reaction could be attributed to the strong patient's motivation for oral hygiene measures. Furthermore the good contouring of the crowns with the gingiva, allows for self-cleansing action mechanism maintenance.

The results of the present study are consistent with the findings of other investigators, who reported that marginal tissue around titanium fixtures, in most examined patients had no gingivitis throughout the study (Buser, Weber and Lang, 1990).

Bleeding index and clinical probing are considered as important and reliable diagnostic parameters in the continuous monitoring of both periodontal and peri-implant tissues (Atassi, 2002). There was a statistically significant difference in mean of BI between both groups at 12 months follow up intervals where the mean BI related to implants placed immediately following teeth extraction with SCTG was significantly more than that related to implants placed immediately following teeth extraction with ADMA. However, the results of the present study demonstrated that the probing depths were almost constant throughout the study periods for both groups and that there was no statistically significant difference in PD throughout the study periods between both groups.

The results of this study demonstrate that when the aim of the clinician is to maintain $\mathrm{KM}$ and esthetic outcomes in cases of IIP in esthetic zone with inherited thin soft tissue biotype, the use of ADMA yields similar results to that of SCTG. Therefore, ADMA may be a useful substitute for SCTG. The advantages of ADMA include avoiding a second surgery for the harvesting of autogenous soft tissue at the donor site, reduction in operative time and it does not require a skilled clinician. However, the high cost of ADMA could be considered as a disadvantage of this material.

Limitations of the present study: Short-term follow-up and Small sample size of each group 


\section{CONCLUSIONS}

\section{Within the limitations of this study, it can be concluded that:}

Using acellular dermal matrix allograft can predictably and sufficiently maintain keratinized mucosa and esthetic outcomes as those achieved through using subepithelial connective tissue when performed in conjunction with immediate dental implants. Acellular dermal matrix allograft can be an alternative to subepithelial connective tissue to maintain soft tissue contour around immediate implant placement in esthetic zone with inherited thin soft tissue biotype.

\section{RECOMMENDATION}

- Future randomized controlled trials should include a longer follow-up and a larger sample size, to assess if immediate implant placement with simultaneous acellular dermal matrix allograft offers long-term soft tissue stability and esthetic outcomes for patients with thin soft tissue biotype.

\section{REFERENCES}

- Agarwal, C., Tarun Kumar, A. B. and Mehta, D. S. (2015) 'Comparative evaluation of free gingival graft and AlloDerm® in enhancing the width of attached gingival: A clinical study', Contemporary Clinical Dentistry, 6(4), pp. 483-8. doi: 10.4103/0976-237X.169838.

- $\quad$ Araújo, M. G. et al. (2005) 'Ridge alterations following implant placement in fresh extraction sockets: An experimental study in the dog', Journal of Clinical Periodontology, 32(6), pp. 645-652 . doi: 10.1111/j.1600051X.2005.00726.x.

- $\quad$ Arora, H. and Ivanovski, S. (2017) 'Correlation between pre-operative buccal bone thickness and soft tissue changes around immediately placed and restored implants in the maxillary anterior region: A 2-year prospective study', Clinical Oral Implants Research, 28(10), pp. 1188- 1194. doi: $10.1111 /$ clr.12939.

- Atassi, F. (2002) 'Periimplant Probing: Positives and Negatives', Implant Dentistry, 11(4), pp. 356-362 . doi: 10.1097/00008505-200211040-00015.
- Batista,E. L. and Batista, F. C. (2001) 'Managing Soft Tissue Fenestrations in Bone Grafting Surgery with an Acellular Dermal Matrix: A Case Report', International Journal of Oral and Maxillofacial Implants, 16(6), pp. 875-9.

- Batista, E. L., Batista, F. C. and Novaes, A. B. (2001) 'Management of Soft Tissue Ridge Deformities With Acellular Dermal Matrix. Clinical Approach and Outcome After 6 Months of Treatment', Journal of Periodontology, 72(2), pp. 265-273. doi: 10.1902/jop.2001.72.2.265.

- $\quad$ Becker, W. and Goldstein, M. (2008) 'Immediate implant placement: Treatment planning and surgical steps for successful outcome', Periodontology 2000, 47(1), pp. 7989. doi: 10.1111/j.1600-0757.2007.00242.x.

- Belser, U.C. et al. (2009) 'Outcome Evaluation of Early Placed Maxillary Anterior Single-Tooth Implants Using Objective Esthetic Criteria: A Cross-Sectional, Retrospective Study in 45 Patients With a 2- to 4-Year Follow-Up Using Pink and White Esthetic Scores', Journal of Periodontology, 80(1), pp. 140-151. doi: 10.1902/ jop.2009.080435.

- Borges, G.J. et al. (2009) 'Acellular dermal matrix as a barrier in guided bone regeneration: A clinical, radiographic and histomorphometric study in dogs', Clinical Oral Implants Research, 20(10), pp. 1105-1115 . doi: 10.1111/j.1600-0501.2009.01731.x.

- $\quad$ Buser, D. et al. (2013) 'Long-Term Stability of Contour Augmentation With Early Implant Placement Following Single Tooth Extraction in the Esthetic Zone A Prospective, Cross-Sectional Study in 41 Patients With a 5- to 9-Year Follow-Up', Journal of Periodontology, 84(11), pp. 1517 1527. doi: 10.1902/jop.2013.120635.

- $\quad$ Buser, D., Martin, W. and Belser, U.C. (2004) 'Optimizing esthetics for implant restorations in the anterior maxilla: anatomic and surgical considerations.' The International journal of oral \& maxillofacial implants, 19 Suppl, pp. 43-61

- $\quad$ Buser, D., Weber, H.P and Lang, N.P. (1990) 'Tissue integration of non-submerged implants. 1-year results of a prospective study with 100 ITI hollow-cylinder and hollow-screw implants.' Clinical Oral Implants Research, 1(1), pp. 33-40. doi: 10.1034/j.1600-0501.1990.010105.x.

- Callan, D. P. and Silverstein, L. H. (1998) 'Use of acellular dermal matrix for increasing keratinized tissue around teeth and implants.', Practical periodontics and aesthetic dentistry : PPAD, 10(6), pp. 731-4 . 
- Caneva, M. et al. (2013) 'Connective tissue grafts in conjunction with implants installed immediately into extraction sockets. An experimental study in dogs', Clinical Oral Implants Research, 24(1), pp. 50-56. doi: 10.1111/j.1600-0501.2012.02450.x.

- Chen, S. T. and Buser, D. (2009) 'Clinical and esthetic outcomes of implants placed in postextraction sites.', The International journal of oral \& maxillofacial implants, 24 Suppl, pp. 186-217.

- Chung, S. et al. (2011) 'Immediate single tooth replacement with subepithelial connective tissue graft using platform switching implants: A case series', Journal of Oral Implantology, 37(5), pp. 559-569. doi: 10.1563/AAIDJOI-D-10-00110.

- Cornelini, R. et al. (2006) 'Immediate restoration of implants placed into fresh extraction sockets for singletooth replacement: A prospective clinical study', The International journal of periodontics \& restorative dentistry, 25(5), pp. 439-47. doi: 10.1016/j.prosdent.2006.03.007.

- Degidi, M. et al. (2013) 'Buccal bone plate in immediately placed and restored implant with Bio-Oss ${ }^{\circledR}$ collagen graft: A 1-year follow-up study', Clinical Oral Implants Research, 24(11), pp. 1201-1205. doi: 10.1111/j.16000501.2012.02561.x.

- $\quad$ Evans, C. D. J. and Chen, S. T. (2008) 'Esthetic outcomes of immediate implant placements', Clinical Oral Implants Research, 19(1), pp. 73-80. doi: 10.1111/j.16000501.2007.01413.x.

- Hutton, C. G. et al. (2018) 'Comparison of two different surgical approaches to increase peri-implant mucosal thickness: A randomized controlled clinical trial', Journal of Periodontology, 89(7), pp. 807-814. doi: 10.1002/ JPER.17-0597.

- J., C. et al. (2011) 'Immediate single-tooth implants in the anterior maxilla: 3 -year results of a case series on hard and soft tissue response and aesthetics', Journal of Clinical Periodontology, 38(8), pp. 746-753

- $\quad$ Kan, J. Y., Rungcharassaeng, K., Lozada, J. L. \& Zimmerman, G. (2011) 'Facial gingival tissue stability following immediate placement and provisionalization of maxillary anterior single implants: a 2-to 8-year follow-up', International Journal of Oral \& Maxillofacial Implants, 26(1), pp. 179-187.

- Kan, J. Y. K., Rungcharassaeng, K. and Lozada, J. L. (2005) 'Bilaminar subepithelial connective tissue grafts for immediate implant placement and provisionalization in the esthetic zone.', Journal of the California Dental Association, 33(11), pp. 65-71

- Landsberg, C. J. (1997) 'Socket seal surgery combined with immediate implant placement: a novel approach for single-tooth replacement.', The International journal of periodontics \& restorative dentistry, 17(2), pp. 140-9. doi: 10.11607/prd.00.0211.

- $\quad$ Liu, C. et al. (2014) 'Reconstruction of attached soft tissue around dental implants by acelluar dermal matrix grafts and resin splint', International Journal of Clinical and Experimental Medicine, 7(12), pp. 4666-76

- Lorenzana, E. R. and Allen, E. P. (2000) 'The singleincision palatal harvest technique: a strategy for esthetics and patient comfort.', The International journal of periodontics \& restorative dentistry, 20(3), pp. 297-305. doi: $10.11607 /$ prd .00 .0363 .

- Migliorati, M. et al. (2015) 'Clinical and Aesthetic Outcome with Post-Extractive Implants with or without Soft Tissue Augmentation: A 2-Year Randomized Clinical Trial', Clinical Implant Dentistry and Related Research, 17(5), pp. 983-995. doi: 10.1111/cid.12194.

- Mombelli, A. et al. (1987) 'The microbiota associated with successful or failing osseointegrated titanium implants', Oral Microbiology and Immunology, 2(4), pp. 145-51. doi: 10.1111/j.1399-302X.1987.tb00298.x.

- Noelken, R., Kunkel, M. and Wagner, W. (2011) 'Immediate implant placement and provisionalization after long-axis root fracture and complete loss of the facial bony lamella.', The International journal of periodontics $\&$ restorative dentistry, $31(2)$, pp. 175-83 . doi: 10.11607/ prd.00.0971.

- Novaes, A. B., Papalexiou, V., et al. (2002) 'Immediate Implant in Extraction Socket with Acellular Dermal Matrix Graft and Bioactive Glass: A Case Report', Implant Dentistry, 11(4), pp. 343-348. doi: 10.1097/00008505200211040-00013.

- $\quad$ Novaes, A. B., Pontes, C. C., et al. (2002) 'The use of acellular dermal matrix allograft for the elimination of gingival melanin pigmentation: case presentation with 2 years of follow-up.', Practical procedures \& aesthetic dentistry : PPAD, 14(8), pp. 619-23.

- $\quad$ Palattella, P., Torsello, F. and Cordaro, L. (2008) 'Two-year prospective clinical comparison of immediate replacement vs. immediate restoration of single tooth in the esthetic 
zone', Clinical Oral Implants Research, 19(11), pp. 11481153. doi: 10.1111/j.1600-0501.2008.01578.x.

- Paolantonio, M. et al. (2001) 'Immediate Implantation in Fresh Extraction Sockets. A Controlled Clinical and Histological Study in Man', Journal of Periodontology, 72(11),pp. 1560-1570 . doi: 10.1902/jop.2001.72.11.1560.

- Park, J. B. (2006) 'Increasing the width of keratinized mucosa around endosseous implant using acellular dermal matrix allograft', Implant Dentistry, 15(3), pp. 275-281. doi: 10.1097/01.id.0000227078.70869.20.

- Park, J. B. (2010) 'Healing of extraction socket grafted with deproteinized bovine bone and acellular dermal matrix: Histomorphometric evaluation', Implant Dentistry, 19(4), pp. 307-313. doi: 10.1097/ID.0b013e3181e5abbc.

- $\quad$ Puisys, A. et al. (2015) 'The use of acellular dermal matrix membrane for vertical soft tissue augmentation during submerged implant placement: A case series', Clinical Oral Implants Research, 26(4), pp. 465-470. doi:10.1111/clr.12401.

- Rungcharassaeng, K. et al. (2012) 'Immediate implant placement and provisionalization with and without a connective tissue graft: an analysis of facial gingival tissue thickness.' The International journal of periodontics $\&$ restorative dentistry, 32(6), pp. 657-63. doi: 10.11607/ prd.00.1114.
- Shulman, J. (1996) 'Clinical evaluation of an acellular dermal allograft for increasing the zone of attached gingiva.', Practical periodontics and aesthetic dentistry : PPAD, 8(2), pp. 201-8.

- Slagter, K. W. et al. (2014) 'Immediate Placement of Dental Implants in the Esthetic Zone: A Systematic Review and Pooled Analysis', Journal of Periodontology, 85(7)pp. e241 -e250 . doi: 10.1902/jop.2014.130632.

- de Souza, S. L. S. et al. (2008) 'Comparative clinical study of a subepithelial connective tissue graft and acellular dermal matrix graft for the treatment of gingival recessions: six- to 12-month changes.', Journal of the International Academy of Periodontology, 10(3), pp. 87-94 .

- Tal, H. (1999) 'Subgingival Acellular Dermal Matrix Allograft for the Treatment of Gingival Recession: A Case Report', Journal of Periodontology, 70(9), pp. 1118-1124. doi: 10.1902/jop.1999.70.9.1118.

- Yoshino, S. et al. (2014) 'Effects of Connective Tissue Grafting on the Facial Gingival Level Following Single Immediate Implant Placement and Provisionalization in the Esthetic Zone: A 1-Year Randomized Controlled Prospective Study', The International Journal of Oral \& Maxillofacial Implants, 29(2), pp. 432-40. doi: 10.11607/ jomi.3379. 